\title{
Analisa Beban Kerja Fisik Operator pada Stasiun Packing melalui Pendekatan Work Sampling (Studi Kasus: PT. P\&P Bangkinang)
}

\author{
Anwardi, ${ }^{1}$ Harpito ${ }^{2}$ \\ 1,2 Jurusan Teknik Industri, Fakultas Sains dan Teknologi, UIN Sultan Syarif Kasim Riau \\ Jl. HR. Soebrantas No. 155 Simpang Baru, Panam, Pekanbaru, 28293 \\ Email: anwardi@uin-suska.ac.id,harpito2@uin-suska.ac.id
}

\begin{abstract}
ABSTRAK
Penelitian ini dilakukan pada PT. P\&P Bangkinang yang bertujuan untuk mengetahui waktu baku serta menentukan jumlah operator pada stasiun packing. Penelitian dilakukan dengan beberapa tahap yaitu pengamatan pendahuluan kemudian dilanjutkan dengan penentuan jumlah pengamatan, pengamatan sampling kerja, mengumpulkan data, melakukan pengolahan data, menganalisa hasil pengolahan data dan terakhir menyimpulkan hasil penelitian. Penelitian dilakukan dengan menggunakan metode work sampling. Metode tersebut dilakukan dengan cara mengamati aktivitas operator dalam menyelesaikan pekerjaannyayang kemudian digunakan untukmenentukan jumlah operator yang dibutuhkan. Hasil akhir yang diperoleh bahwa waktu baku untuk operator (1) 7,9 menit dan operator (2) 9,2 menit. Untuk kondisi awal beban kerja yang diterima oleh operator sebesar BK $>1(1,3)$, yang dikategorikan kondisi berat, tetapi setelah dilakukan penelitian dengan mengusulkan penambahan 1 orang operator, maka beban kerja yang diterima sebesar $\mathrm{BK}<1(0,86)$ yang dikategorikan ringan.
\end{abstract}

Kata Kunci: Beban Kerja, Waktu Baku, Work Sampling

\section{Pendahuluan}

Penggunaan serta perkembangan karet saat ini sangatlah pesat, hal ini dapat dilihat dari banyaknya industri-industri yang menggunakan karet, bahkan dizaman modern ini penggunaan barang berbahan karet sangatlah digemari oleh masyarakat. Data International Rubber Study Group (IRSG) tahun 2015 menunjukkan peningkatan yang mencapai 25.000.000 Ton/Tahun. Faktor-faktor yang mempengaruhi kualitas produksi karet adalah tenaga kerja, fasilitas kerja dan lingkungan kerja yang akan berdampak pada beban kerja fisik operator. Beban kerja fisik merupakan kegiatan yang mengakibatkan pengeluaran energi dengan menggunakan otot sebagai kegiatan sentral yang dapat mempengaruhi diri seseorang untuk menjalankan tugas-tugas yang dikerjakannya sesuai dengan kondisi fisik yang maksimal. Untuk mengoptimalkan kemampuan kerja, perlu diperhatikan pengeluaran energi dan pemulihan energi selama proses kerja berlangsung (Pracinasari, 2013).

PT. Perdagangan dan Perindustrian Bangkinang (PT. P\&P Bangkinang) merupakan perusahaan yang bergerak dibidang indutri pengolahan karet remah (crumbrubber). Karet remah yang diproduksi memiliki kualitas yang bervariasi diantaranya Standar Indonesia Rubber (SIR) 10 dan SIR 20. Salah satu stasiun kerja dalam kegiatan produksi di Perusahaan tersebut adalah stasiun packing yang memegang peranan penting, karena pada bagian inilah dilakukan finishing produk akhir. Kegiatan pengemasan (packing) dilakukan dengan sedemikian rupa hingga sampai ke tangan customer sesuai dengan keinginan customer. Perusahaan ini hanya mampu menyelesaikan pengemasan sebanyak 60 batch setiap harinya, sementara target pengemasan yang harus diselesaikan berdasarkan hasil wawancara yaitu mencapai 75 sampai 80 batch/hari. Untuk mencapai target pengemasan pada PT. P\&P Bangkinang, maka perlu dilakukan peningkatan 
kinerja operator melalui pengukuran kerja dengan metode work sampling. Metode tersebut berguna untuk mengetahui kecepatan kerja dari seorang operator dengan menghitung faktor-faktor yang mempengaruhinya, baik waktu kosong atau menganggur (idle time) dari mesin atau fasilitas produksi guna memenuhi target pengemasan perhari. Hasil studi ini akan dapat dipakai pula sebagai dasar penetapan tugas dan jadwal kerja yang lebih efektif dan efisien bagi operator maupun mesin (Wignjosoebroto, 2008), sehingga dapat diketahui waktu standar yang dibutuhkan oleh seorang operator untuk menyelesaikan suatu pekerjaan di stasiun packing.

Pengukuran kerja ini akan memberikan kemudahan bagi pihak PT. P\&P Bangkinang untuk mengetahui waktu standar yang diperlukan oleh setiap operator dalam menyelesaikan pekerjaannya, pengontrolan kerja dan dan kemudahan lainnya. Kondisi inilah yang mendasari dilakukannya penelitian untuk menentukan waktu standar dan jumlah tenaga kerja berdasarkan analisis kerja fisik operator di stasiun packing dengan menggunakan metode work sampling.

\section{Tinjauan Pustaka}

\section{Beban Kerja}

Pada dasarnya, aktivitas manusia dapat digolongkan menjadi kerja fisik (otot) dan kerja mental (otak). Meskipun tidak dapat dipisahkan, namun masih dapat dibedakan pekerjaan dengan dominasi fisik dan pekerjaan dengan dominasi mental. Aktivitas fisik dan mental ini menimbulkan konsekuensi, yaitu munculnya beban kerja (Widyanti, 2010). Beban kerja dapat didefenisikan sebagai perbedaan antara kemampuan pekerja dengan tuntutan pekerjaan. Jika kemampuan pekerja lebih tinggi daripada tuntutanpekerjaan, akan muncul perasaan bosan. Sebaliknya, jika kemampuan pekerja lebih rendah daripada tuntutan pekerjaan, maka akan muncul kelelahan yang berlebihan (Widyanti, 2010).

\section{Beban Kerja Fisik}

Beban kerja fisik (physical workload) merupakan beban yang diterima oleh fisik akibat pelaksanaan kerja. Prinsip dasar dalam ergonomi adalah bagaimana agar demand $<$ capacity, sehingga perlu diupayakan agar beban kerja fisik yang diterima tubuh saat bekerja tidak melebihi kapasitas fisik manusia yang bersangkutan (Ferdian, 2013). Formula yang digunakan dalam menentukan beban kerja adalah sebagai berikut:

$$
\mathrm{BK}=\frac{\mathrm{WB} \text { Total }}{\text { Total Menit Pengamatan }}
$$

Beban kerja yang yang dikatakan tinggi apabila nilai dari perhitungan beban kerja $>1$, beban kerja sedang $=1$, sedangkan beban kerja ringan $<1$ (Izzhati, 2012)

\section{Penentuan Jadwal Waktu Pengamatan Secara Acak (Random)}

Pada langkah ini dilakukan sejumlah pengamatan terhadap aktifitas kerja untuk selang waktu yang diambil secara acak. Untuk ini biasanya satu hari kerja dibagi ke dalam satuan-satuan waktu yang besarnya ditentukan oleh pengukur. Biasanya panjang satu satuan waktu tidak terlalu panjang. Berdasarkan satu satuan waktu inilah saat-saat kunjungan ditentukan (Sutalaksana 1976).

Misalnya satu-satuan waktu panjangnya 5 menit, jadi satu hari kerja (7 jam) mempunyai 84 satuan waktu. Ini berarti jumlah kunjungan perhari tidak lebih dari 84 kali. Jika dalam satu hari dilakukan 36 kali kunjungan maka dengan bantuan tabel bilangan acak ditentukan saat-saat kunjungan tersebut.

\section{Pengujian Statistik}

\section{Uji Keseragaman}

Uji keseragaman data perlu kita lakukan terlebuh dahulu sebelum kita menggunakan data yang diperoleh guna menetapkan waktu standar atau waktu baku. Uji keseragamn dapat dilakukan dengan cara visual atau mengaplikasikan peta kontrol. Langkah-langkah untuk menguji keseragaman data adalah sebagai berikut (Munandar, 2013):

1. Mengelompokkan data-data yang ada ke dalam beberapa subgrup

2. Perhitungan harga rata-rata dari rata-rata subgrup dengan rumus (Munandar, 2013): 


$$
\tilde{X}=\frac{\sum \mathrm{Xi}}{\mathrm{N}}
$$

Keterangan:

$\sum \mathrm{Xi}=$ Data Pengamatan

$$
\mathrm{N}=\text { Jumlah }
$$

Untuk menghitung

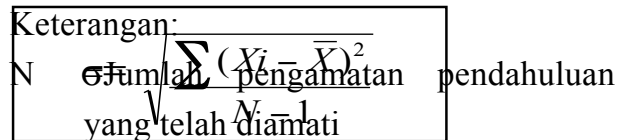
yang telah diamati

$\mathrm{x} \quad$ =Waktu penyelesaian yang teramati selama pengukuran yang telah dilakukan

3. Menentukan batas kontrol atas (BKA) dan batas kontrol bawah (BKB)

Suatu data dikatakan seragam jika semua data berada diantara dua batas kontrol, yaitu batas kontrol atas (BKA) dan batas kontrol bawah (BKB). Adapun perumusan dari batas kontrol atas dan batas kontrol bawah adalah sebagai berikut (Wignjosoebroto 2012):

\section{Uji Kecukupan}

Banyaknya pengamatan yang harus dilakukan dalam sampling kerja akan dipengaruhi oleh dua faktor utama, yaitu tingkat ketelitian (degree of accuracy) dari dan tingkat kepercayaan (level of convidence) dari hasil pengamatan. Dengan asumsi bahwa terjadinya kejadian seorang operator akan bekerja atau menganggur mengikuti pola distribusi normal (Izzhati, 2012). Pada penelitian ini menggunakan tingkat ketelitian 5\% dan tingkat kepercayaan 95\% (Sutalaksana, 1979)

$$
\mathrm{N}^{\prime}=\frac{1600(1-\mathrm{P})}{\mathrm{P}}
$$

Keterangan:

$\mathrm{P}=$ Persentase produktif

$\mathrm{N}^{\prime}=$ Data yang dibutuhkan

Pengamatan dianggap apabila $\mathrm{N}^{\prime} \leq \mathrm{N}$, maka jumlah data sudah cukup dan apabila $\mathrm{N}^{\prime}>\mathrm{N}$, maka jumlah data belum cukup.

\section{Persentase Waktu Produktif Setiap Elemen Kerja}

Persentase waktu produktif merupakan perhitungan yang sangat penting untuk menentukan waktu siklus pengerjaan suatu produk. Waktu ini juga biasa dijadikan untuk waktu siklus perstasiun atau elemen kerja dari pembuatan produk. Dalam melakukan perhitungan waktu produktif atau yang disebut juga dengan jumlah menit produktif, hal yang perlu diketahui terlebih dahulu adalah perhitungan persentase produktif dari data produktif dan non produktif yang telah didapatkan dengan menggunakan rumus (Izzhati, 2012).

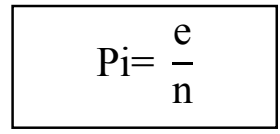

Keterangan:

$\mathrm{Pi}=$ Persentase produktif elemen kerja

e = Jumlah elemen kerja

$\mathrm{n}=$ Jumlah pengamatan

Perhitungan jumlah menit produktif akan didapat jika data jam dalam satu hari jam kerja telah diketahui. Selain itu, jumlah pengamatan juga sangat berpengaruh untuk mendapatkan jumlah menit produktif. Sebagai contoh data bekerja pekerjaan dalam satu hari adalah 7 jam dan jumlah pengamatan yang dilakukan sebanyak 5 hari. Maka kita akan mendapat total menit pengamatan sebesar 2100 menit. Apabila diketahui dari persentase produktif dari elemen kerja sebesar 0,06. Adapun rumusnya adalah (Izzhati, 2012):

Keterangan:

$\mathrm{Me}=\mathrm{Pi}$ x Total Menit Pengamatan

\section{Waktu Siklus}

Waktu yang diperlukan untuk melaksanakan elemen-elemen kerja pada umumnya akan diselesaikan dalam waktu yang sama persis. Sekalipun operator bekerja pada kecepatan normal atau uniform, tiap-tiap elemen dalam siklus yang berbeda tidak selalu akan bisa diselesaikan dalam waktu yang persis sama (Rinawati, 2012). Berikut rumus untuk siklus per elemen kerja (Izzhati, 2012): 
Keterangan:

$$
\mathrm{WSU}=\frac{\mathrm{Me}}{\mathrm{OIU}}
$$

WSU $=$ Waktu siklus per elemen kerja

$\mathrm{Me}=$ Jumlah menit produktif

OIU =Jumlah produktif per elemen kerja pengamatan keseluruhan

\section{Penyesuaian dan Kelonggaran dalam \\ Pengukuran Kerja}

Berikut ini adalah beberapa cara untuk pemberian penyesuaian dalam pengukuran kerja (Sutalaksana, 1979):

1. Metode Persentase

Cara persentase dilakukan dengan mempertimbangkan faktor penyesuaian sepenuhnya ditentukan oleh pengukur melalui pengamatannya selama melakukan pengukuran.

2. Metode Shumard

Memberikan patokan-patokan penilaian melalui kelas-kelas performance kerja dimana setiap kelas mempunyai nilai sendiri-sendiri.

Tabel 2.1 Penyesuaian Metode Shumard

\begin{tabular}{|c|c|}
\hline Kelas & Penyesuaian \\
\hline Superfast & 100 \\
\hline Fast + & 95 \\
\hline Fast & 90 \\
\hline Fast - & 85 \\
\hline Excellent & 80 \\
\hline Good + & 75 \\
\hline Good & 70 \\
\hline Good- & 65 \\
\hline Normal & 60 \\
\hline Fair + & 55 \\
\hline Fair & 50 \\
\hline Fair - & 45 \\
\hline Poor & 40 \\
\hline
\end{tabular}

(Sumber: Sutalaksana, 1979)

\section{Metode Westinghouse}

Cara westinghouse mengarahkan penilaian pada 4 faktor yang dianggapmenentukan kewajaran atau ketidakwajaran dalam bekerja. Adapun 4 faktor tersebut antara lain:
a. Keterampilan atau skill,
b. Usaha atau effort
c. Kondisi kerja atau condition
d. Konsistensi

Tabel 2.2 Penyesuaian Metode Westinghouse

\begin{tabular}{|c|c|c|c|}
\hline Faktor & Kelas & Lambang & Penyesuaian \\
\hline \multirow{11}{*}{ Ketrampilan } & \multirow{2}{*}{ Super Skill } & A1 & $+0,15$ \\
\hline & & A2 & $+0,13$ \\
\hline & \multirow{2}{*}{ Excellent } & B1 & $+0,11$ \\
\hline & & B2 & $+0,08$ \\
\hline & \multirow{2}{*}{ Good } & $\mathrm{C} 1$ & $+0,06$ \\
\hline & & $\mathrm{C} 2$ & $+0,03$ \\
\hline & Average & $\mathrm{D}$ & $+0,00$ \\
\hline & \multirow{2}{*}{ Fair } & E1 & $-0,05$ \\
\hline & & E2 & $-0,10$ \\
\hline & \multirow{2}{*}{ Poor } & F1 & $-0,16$ \\
\hline & & F2 & $-0,22$ \\
\hline \multirow{11}{*}{ Usaha } & \multirow{2}{*}{ Excessive } & A1 & $+0,13$ \\
\hline & & $\mathrm{A} 2$ & $+0,12$ \\
\hline & \multirow{2}{*}{ Excellent } & B1 & $+0,10$ \\
\hline & & B2 & $+0,08$ \\
\hline & \multirow{2}{*}{ Good } & $\mathrm{C} 1$ & $+0,05$ \\
\hline & & $\mathrm{C} 2$ & $+0,02$ \\
\hline & Average & $\mathrm{D}$ & $-0,00$ \\
\hline & \multirow{2}{*}{ Fair } & E1 & $-0,04$ \\
\hline & & E2 & $-0,08$ \\
\hline & \multirow{2}{*}{ Poor } & F1 & $-0,12$ \\
\hline & & $\mathrm{F} 2$ & $-0,17$ \\
\hline \multirow{6}{*}{$\begin{array}{c}\text { Kondisi } \\
\text { Kerja }\end{array}$} & Ideal & $\mathrm{A}$ & $+0,06$ \\
\hline & Excellently & $\mathrm{B}$ & $+0,04$ \\
\hline & Good & $\mathrm{C}$ & $+0,02$ \\
\hline & Average & $\mathrm{D}$ & $+0,00$ \\
\hline & Fair & $\mathrm{E}$ & $-0,03$ \\
\hline & Poor & $\mathrm{F}$ & $-0,07$ \\
\hline \multirow{6}{*}{$\begin{array}{c}\text { Konsis } \\
\text { tensi }\end{array}$} & Perfect & $\mathrm{A}$ & $+0,04$ \\
\hline & Excellent & B & $+0,03$ \\
\hline & Good & $\mathrm{C}$ & $+0,01$ \\
\hline & Average & $\mathrm{D}$ & 0,00 \\
\hline & Fair & $\mathrm{E}$ & $-0,02$ \\
\hline & Poor & $\mathrm{F}$ & $-0,02$ \\
\hline
\end{tabular}

(Sumber: Sutalaksana, 1979)

4. Metode Objektif

Cara objektif memperhatikan 2 faktor yaitu kecepatan kerja dan tingkat kesulitan pekerjaan. Kedua faktor inilah yang dipandang secara bersama-sama menentukan berapa harga $\mathrm{P}$ untuk mendapatkan waktu normal. Kecepatan kerja adalah kecepatan dalam melakukan pekerjaan dalam pengertian biasa. Jika 
operator bekerja dengan kecepatan wajar maka diberi nilai satu. Cara menentukan besarnya $\mathrm{P}$ tidak berbeda dengan cara menentukan faktor penyesuaian dengan cara persentase, perbedannya terletak pada yang dinilai (Trisnawati, 2007).

5. Metode Bedaux dan Sintesa

Dua cara lain yang dikembangkan untuk lebih mengobjektifkan penyesuaian adalah cara Bedaux dab cara Sintesa. Pada dasarnya cara Bedaux tidak banyak berbeda dengan cara Shumard, hanya saja nilai-nilai pada cara Bedaux dinyatakan dalam "B" Sedangkan cara Sintesa agar berbeda debgan cara-cara lain, dimana dalam cara ini waktu penyelesaian setiap elemen gerakan dibandingkan dengan harga-harga yang diperoleh dari tabel-tabel data waktu gerakan untuk dihitung harga rata-ratanya.harga rata-rata yang dinilai sebagai penyesuaian bagi satu siklus yang bersangkutan(Trisnawati, 2007).

\section{Metode Penelitian}

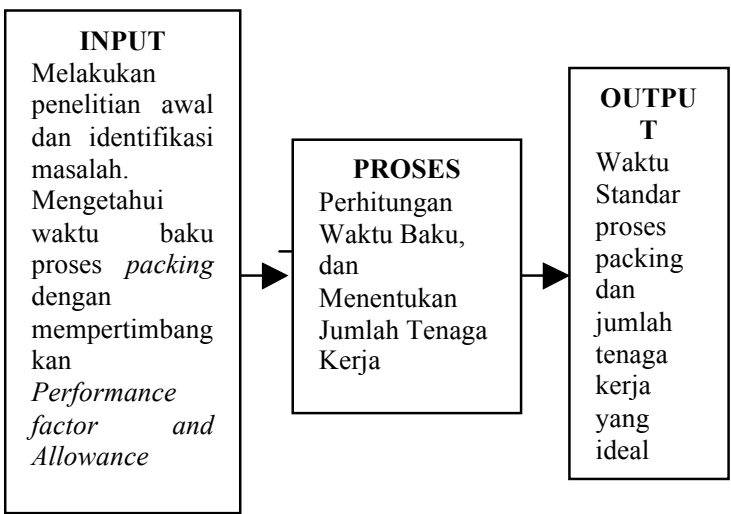

\section{Hasil dan Pembahasan}

\section{Menentukan Jadwal Pengamatan}

Jadwal pengamatan yang dilakukan selama 8 jam dimulai dari jam 08.00 WIB-17.00 WIB dan waktu interval pengamatan selama 5 menit, banyak nya waktu pengamatan dalam satu hari maka diperlukan pembangkit bilangan acak yang berfungsi untuk menentukan jadwal pengamatan selama waktu kerja (8 jam) dapat dilihat dari perhitungan sebagai berikut:

Banyak pengamatan $=\frac{\text { Jumlah Jam Kerja x } 60 \text { Menit }}{\text { Waktu Interval }}$

$$
\begin{aligned}
& =\frac{8 \mathrm{jam} \times 60 \mathrm{menit}}{5 \mathrm{menit}} \\
& =96 \text { pengamatan } / \text { hari }
\end{aligned}
$$

Berdasarkan perhitungan jadwal pengamatan maka jumlah kunjungan per hari tidak boleh lebih dari 96 kunjungan. Berikut ini adalah daftar bilangan acak yang tepilih:

3.1 Bilangan Acak yang Terpilih

\begin{tabular}{|c|c|c|c|c|c|c|c|c|c|c|}
\hline \multicolumn{10}{|c|}{ Bilangan Acak Terpilih } \\
\hline 3 & 4 & 5 & 7 & 11 & 13 & 18 & 20 & 21 & 22 & 23 \\
\hline 32 & 33 & 34 & 35 & 37 & 39 & 45 & 47 & 51 & 52 & 55 \\
\hline 63 & 68 & 70 & 74 & 76 & 79 & 84 & 86 & 89 & 92 & 93 \\
\hline 94 & 95 & \multicolumn{10}{|c|}{}
\end{tabular}

Berdasarkan hasil pengamatan dilapangan, maka diperoleh hasil kerja produktif dan nonproduktif. Berikut hasil rekapitulasi kerja produktif dan nonproduktif.

Tabel 3.2 Rekapitulasi Kerja Produktif dan Non produktif

\begin{tabular}{|c|c|c|}
\hline Kegiatan & Operator 1 & Operator 2 \\
\hline Produktif & 110 & 104 \\
\hline Non Produktif & 7 & 7 \\
\hline $\begin{array}{c}\text { Jumlah } \\
\text { Pengamatan }\end{array}$ & 117 & 111 \\
\hline Total \% Produktif & $94 \%$ & $94 \%$ \\
\hline
\end{tabular}

\section{Pengolahan Data}

\section{Uji Statistik}

dalam pengolahan data, dilakukan uji statisti seperti uji keseragaman dan kecukupan data, dimana uji keseragaman menggunakan tingkat kepercayaan 95\% dan tingkat keyakinan 5\%. Berikut hasil perhitngan uji keseragaman dan kecukupan data yang ditampilkan dalam bentuk grafik.

\section{Uji Keseragaman Operator 2}

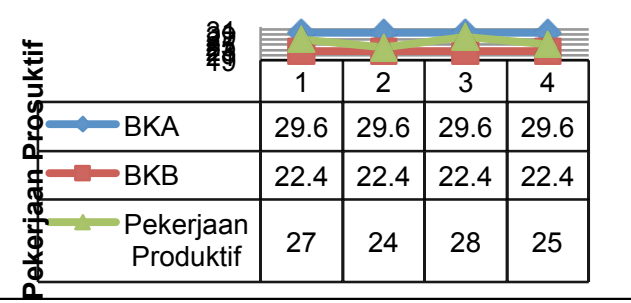




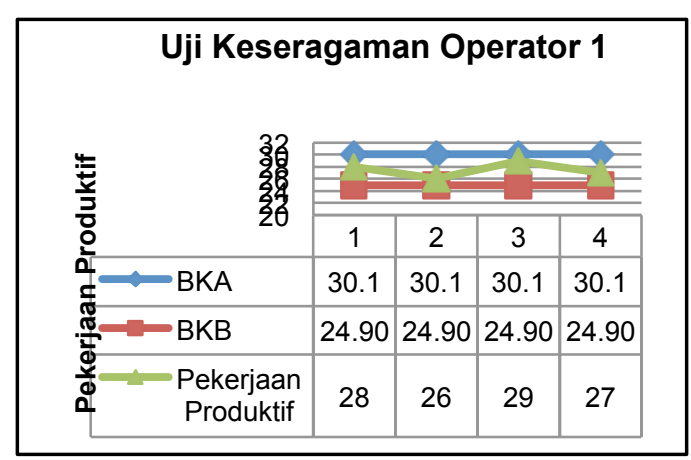

Gambar 3.2 Uji Keseragaman

Sedangkan pada uji kecukupan, data berada dalam keadaan cukup, baik operator 1 maupun operator 2 .

1. Operator 1

$$
\begin{aligned}
\mathrm{P} & =\frac{\text { Jumlah Elemen Kerja Produktif }}{\text { Jumlah Pengamatan }} \\
\mathrm{P} & =\frac{110}{117} \\
& =0,94 \\
\mathrm{~N}^{\prime} & =\frac{1600(1-0,94)}{0,94} \\
\mathrm{~N}^{\prime} & =102 \\
\mathrm{~N} & =117
\end{aligned}
$$

Jadi nilai $\mathrm{N}^{\prime}<\mathrm{N}$ maka data yang diukur telah cukup

1. Operator 2

$$
\begin{aligned}
\mathrm{P} & =\frac{\text { Jumlah Elemen Kerja Produktif }}{\text { Jumlah Pengamatan }} \\
\mathrm{P} & =\frac{104}{111} \\
& =0,94 \\
\mathrm{~N}^{\prime} & =\frac{1600(1-0,94)}{0,94} \\
\mathrm{~N}^{\prime} & =102 \\
\mathrm{~N} & =111
\end{aligned}
$$

Jadi nilai N' < N maka data yang diukur telah cukup.

\section{Perhitungan Persentase Waktu Per Elemen KerjaProduktif}

Tabel 3.3 Persentase Waktu Per Elemen KerjaProduktif

\begin{tabular}{|c|c|l|c|}
\hline \multicolumn{3}{|c|}{ Persentase Waktu Per Elemen KerjaProduktif } \\
\hline \multicolumn{2}{|c|}{ Operator 1 } & \multicolumn{1}{c|}{ Operator 2 } \\
\hline $\begin{array}{c}\text { Elemen } \\
\text { Pekerjaan }\end{array}$ & $\begin{array}{l}\text { Persentase } \\
\text { Produktif }\end{array}$ & \multicolumn{1}{c|}{$\begin{array}{c}\text { Elemen } \\
\text { Pekerjaan }\end{array}$} & $\begin{array}{l}\text { Persentase } \\
\text { Produktif }\end{array}$ \\
\hline $\begin{array}{l}\text { Memotong } \\
\text { sudut karet }\end{array}$ & 0,23 & $\begin{array}{l}\text { Menggulung dan } \\
\text { melipat plastik }\end{array}$ & 0,24 \\
\hline $\begin{array}{l}\text { Memasukkan } \\
\text { karet ke plastik }\end{array}$ & 0,22 & $\begin{array}{l}\text { Mengambil karet } \\
\text { dari mesin } \\
\text { pengepresan dan } \\
\text { meletakkan ke } \\
\text { troli }\end{array}$ & 0,21 \\
\hline $\begin{array}{l}\text { Menimbang } \\
\text { karet }\end{array}$ & 0,24 & $\begin{array}{l}\text { Mengambil } \\
\text { kotoran }\end{array}$ & 0,25 \\
\hline
\end{tabular}

\begin{tabular}{|l|l|l|l|}
\hline & & $\begin{array}{l}\text { (kontaminasi) } \\
\text { dari karet }\end{array}$ & \\
\hline $\begin{array}{l}\text { Pengecekan } \\
\text { karet }\end{array}$ & 0,23 & $\begin{array}{l}\text { Mengatur jalan } \\
\text { lintasan karet } \\
\text { agar tidak } \\
\text { menumpuk }\end{array}$ & 0,22 \\
\hline
\end{tabular}

Perhitungan Menit Pengamatan Per Elemen Kerja Produktif

Tabel 3.4 Rekapitulasi Menit Pengamatan Per Elemen Kerja Produktif

\section{Menit Pengamatan Per Elemen Kerja Produktif}

\begin{tabular}{|l|c|l|c|}
\hline \multicolumn{2}{|c|}{ Operator 1 } & \multicolumn{2}{c|}{ Operator 2 } \\
\hline $\begin{array}{c}\text { Elemen } \\
\text { Pekerjaan }\end{array}$ & $\begin{array}{c}\text { Jumlah } \\
\text { Menit }\end{array}$ & $\begin{array}{c}\text { Elemen } \\
\text { Pekerjaan }\end{array}$ & $\begin{array}{c}\text { Jumlah } \\
\text { Menit }\end{array}$ \\
\hline $\begin{array}{l}\text { Memotong } \\
\text { sudut karet }\end{array}$ & 40,2 & $\begin{array}{l}\text { Menggulung } \\
\text { dan melipat } \\
\text { plastik }\end{array}$ & 42 \\
\hline $\begin{array}{l}\text { Memasukkan } \\
\text { karet ke } \\
\text { plastik }\end{array}$ & 38,5 & $\begin{array}{l}\text { Mengambil } \\
\text { karet dari } \\
\text { mesin } \\
\text { pengepresan } \\
\text { dan } \\
\text { meletakkan ke } \\
\text { troli }\end{array}$ & 36,7 \\
\hline $\begin{array}{l}\text { Menimbang } \\
\text { karet }\end{array}$ & 42 & $\begin{array}{l}\text { Mengambil } \\
\text { kotoran } \\
\text { (kontaminasi) } \\
\text { dari karet }\end{array}$ & 43,7 \\
\hline $\begin{array}{l}\text { Pengecekan } \\
\text { karet }\end{array}$ & 40,2 & $\begin{array}{l}\text { Mengatur jalan } \\
\text { lintasan karet } \\
\text { agar tidak } \\
\text { menumpuk }\end{array}$ & 38,5 \\
\hline
\end{tabular}

\section{Perhitungan Waktu Siklus}

Tabel 3.5 Rekapitulasi Hasil Perhitungan Waktu Siklus

\begin{tabular}{|l|c|l|c|}
\hline \multicolumn{3}{|c|}{ Waktu Siklus Per Elemen Kerja Produktif } \\
\hline \multicolumn{2}{|c|}{ Operator 1 } & \multicolumn{2}{c|}{ Operator 2 } \\
\hline $\begin{array}{c}\text { Elemen } \\
\text { Pekerjaan }\end{array}$ & $\begin{array}{c}\text { Waktu } \\
\text { Siklus } \\
\text { (menit) }\end{array}$ & \multicolumn{1}{|c|}{$\begin{array}{c}\text { Elemen } \\
\text { Pekerjaan }\end{array}$} & $\begin{array}{c}\text { Waktu } \\
\text { Siklus } \\
\text { (menit) }\end{array}$ \\
\hline $\begin{array}{l}\text { Memotong } \\
\text { sudut karet }\end{array}$ & 1,43 & $\begin{array}{l}\text { Menggulung } \\
\text { dan melipat } \\
\text { plastik }\end{array}$ & 1,56 \\
\hline $\begin{array}{l}\text { Memasukkan } \\
\text { karet ke plastik }\end{array}$ & 1,48 & $\begin{array}{l}\text { Mengambil } \\
\text { karet dari } \\
\text { mesin } \\
\text { pengepresan } \\
\text { dan } \\
\text { meletakkan ke } \\
\text { troli }\end{array}$ & 1,52 \\
\hline $\begin{array}{l}\text { Menimbang } \\
\text { karet }\end{array}$ & 1,44 & $\begin{array}{l}\text { Mengambil } \\
\text { kotoran } \\
\text { kontaminasi) } \\
\text { dari karet }\end{array}$ & 1,56 \\
\hline $\begin{array}{l}\text { Pengecekan } \\
\text { karet }\end{array}$ & 1,48 & $\begin{array}{l}\text { Mengatur jalan } \\
\text { lintasan karet }\end{array}$ & 1,54 \\
\hline
\end{tabular}




\begin{tabular}{|c|c|c|c|}
\hline & & \multicolumn{2}{|l|}{$\begin{array}{l}\text { agar tidak } \\
\text { menumpuk }\end{array}$} \\
\hline Total & 5,83 & Total & 6,18 \\
\hline \multicolumn{4}{|c|}{$\begin{array}{l}\text { Perhitungan Faktor Kelonggaran Per Elemen } \\
\text { KerjaProduktif } \\
\text { Tabel 3.6 Rekapitulasi Perhitungan Faktor } \\
\text { Kelonggaran Per Elemen KerjaProduktif }\end{array}$} \\
\hline \multicolumn{2}{|c|}{ Operator 1} & \multicolumn{2}{|c|}{ Operator 2} \\
\hline $\begin{array}{l}\text { Elemen } \\
\text { Pekerjaan }\end{array}$ & $\begin{array}{c}\text { Kelonggaran } \\
(\%)\end{array}$ & $\begin{array}{l}\text { Elemen } \\
\text { Pekerjaan }\end{array}$ & $\begin{array}{c}\text { Kelonggaran } \\
(\%)\end{array}$ \\
\hline $\begin{array}{l}\text { Memotong } \\
\text { sudut karet }\end{array}$ & 22 & $\begin{array}{l}\text { Menggulung } \\
\text { dan melipat } \\
\text { plastik }\end{array}$ & 21 \\
\hline $\begin{array}{l}\text { Memasukkan } \\
\text { karet ke } \\
\text { plastik }\end{array}$ & 30 & $\begin{array}{l}\text { Mengambil } \\
\text { karet dari } \\
\text { mesin } \\
\text { pengepresan } \\
\text { dan } \\
\text { meletakkan } \\
\text { ke troli }\end{array}$ & 41 \\
\hline $\begin{array}{l}\text { Menimbang } \\
\text { karet }\end{array}$ & 26,5 & $\begin{array}{l}\text { Mengambil } \\
\text { kotoran } \\
\text { (kontaminasi) } \\
\text { dari karet }\end{array}$ & 26,5 \\
\hline $\begin{array}{l}\text { Pengecekan } \\
\text { karet }\end{array}$ & 28 & $\begin{array}{l}\text { Mengatur } \\
\text { jalan lintasan } \\
\text { karet agar } \\
\text { tidak } \\
\text { menumpuk }\end{array}$ & 22 \\
\hline
\end{tabular}

\section{Perhitungan Faktor Penyesuaian Per Elemen KerjaProduktif}

Tabel 3.7 Rekapitulasi Perhitungan Faktor Penyesuaian Per Elemen KerjaProduktif

\begin{tabular}{|c|c|l|c|}
\hline \multicolumn{2}{|c|}{ Operator 1 } & \multicolumn{2}{c|}{ Operator 2 } \\
\hline \multicolumn{1}{|c|}{$\begin{array}{c}\text { Plemen } \\
\text { Pekerjaan }\end{array}$} & Penyesuaian & $\begin{array}{c}\text { Elemen } \\
\text { Pekerjaan }\end{array}$ & Penyesuaian \\
\hline $\begin{array}{l}\text { Memotong } \\
\text { sudut karet }\end{array}$ & 1,10 & $\begin{array}{l}\text { Menggulung } \\
\text { dan melipat } \\
\text { plastik }\end{array}$ & 1,10 \\
\hline $\begin{array}{l}\text { Memasukkan } \\
\text { karet ke } \\
\text { plastik }\end{array}$ & 1,11 & $\begin{array}{l}\text { Mengambil } \\
\text { karet dari } \\
\text { mesin } \\
\text { pengepresan } \\
\text { dan } \\
\text { meletakkan } \\
\text { ke troli }\end{array}$ & 1,16 \\
\hline $\begin{array}{l}\text { Menimbang } \\
\text { karet }\end{array}$ & 1,07 & $\begin{array}{l}\text { Mengambil } \\
\text { kotoran } \\
\text { kontaminasi) } \\
\text { dari karet }\end{array}$ & 1,14 \\
\hline $\begin{array}{l}\text { Pengecekan } \\
\text { karet }\end{array}$ & 1,1 & $\begin{array}{l}\text { Mengatur } \\
\text { jalan lintasan } \\
\text { karet agar } \\
\text { tidak } \\
\text { menumpuk }\end{array}$ & 1,5 \\
\hline Rata-Rata & 1,12 & \begin{tabular}{l} 
Rata-Rata \\
\hline
\end{tabular} & 1,2 \\
\hline
\end{tabular}

Perhitungan Waktu Normal

Tabel 3.8 Rekapitulasi Perhitungan Waktu Normal

\begin{tabular}{|l|c|l|c|}
\hline \multicolumn{2}{|c|}{ Operator 1 } & \multicolumn{2}{c|}{ Operator 2 } \\
\hline \multicolumn{1}{|c|}{$\begin{array}{c}\text { Elemen } \\
\text { Pekerjaan }\end{array}$} & $\begin{array}{c}\text { Waktu } \\
\text { Normal } \\
\text { (Menit) }\end{array}$ & \multicolumn{1}{c|}{$\begin{array}{c}\text { Elemen } \\
\text { Pekerjaan }\end{array}$} & $\begin{array}{c}\text { Waktu } \\
\text { Normal } \\
\text { (Menit) }\end{array}$ \\
\hline $\begin{array}{l}\text { Memotong sudut } \\
\text { karet }\end{array}$ & 1,61 & $\begin{array}{l}\text { Menggulung dan } \\
\text { melipat plastik }\end{array}$ & 1,83 \\
\hline $\begin{array}{l}\text { Memasukkan } \\
\text { karet ke plastik }\end{array}$ & 1,60 & $\begin{array}{l}\text { Mengambil karet } \\
\text { dari mesin } \\
\text { pengepresan dan } \\
\text { meletakkan ke } \\
\text { troli }\end{array}$ & 1,82 \\
\hline $\begin{array}{l}\text { Menimbang } \\
\text { karet }\end{array}$ & 1,62 & $\begin{array}{l}\text { Mengambil } \\
\text { kotoran } \\
\text { (kontaminasi) } \\
\text { dari karet }\end{array}$ & 1,83 \\
\hline $\begin{array}{l}\text { Pengecekan } \\
\text { karet }\end{array}$ & 1,60 & $\begin{array}{l}\text { Mengatur jalan } \\
\text { lintasan karet } \\
\text { agar tidak } \\
\text { menumpuk }\end{array}$ & 1,83 \\
\hline \multicolumn{1}{|c|}{ Total } & 6,43 & \multicolumn{1}{|c|}{ Total } & 7,31 \\
\hline
\end{tabular}

\section{Perhitungan Waktu Baku}

Tabel 3.9 Rekapitulasi Perhitungan Waktu Baku

\begin{tabular}{|l|c|l|c|}
\hline \multicolumn{2}{|c|}{ Operator 1 } & \multicolumn{2}{c|}{ Operator 2 } \\
\hline \multicolumn{1}{|c|}{$\begin{array}{c}\text { Plemen } \\
\text { Pekerjaan }\end{array}$} & $\begin{array}{c}\text { Waktu } \\
\text { Baku } \\
\text { (Menit) }\end{array}$ & \multicolumn{1}{c|}{$\begin{array}{c}\text { Elemen } \\
\text { Pekerjaan }\end{array}$} & $\begin{array}{c}\text { Waktu } \\
\text { Baku } \\
\text { (Menit) }\end{array}$ \\
\hline $\begin{array}{l}\text { kemotong sudut } \\
\text { kemasukkan } \\
\text { karet ke plastik }\end{array}$ & 1,9 & $\begin{array}{l}\text { Menggulung dan } \\
\text { melipat plastik }\end{array}$ & 2,2 \\
\hline $\begin{array}{l}\text { Menimbang } \\
\text { karet }\end{array}$ & 2 & $\begin{array}{l}\text { Mengambil karet } \\
\text { dari mesin } \\
\text { pengepresan dan } \\
\text { meletakkan ke } \\
\text { troli }\end{array}$ & 2,5 \\
\hline $\begin{array}{l}\text { Pengecekan } \\
\text { karet }\end{array}$ & 2 & $\begin{array}{l}\text { Mengambil } \\
\text { kotoran } \\
\text { (kontaminasi) } \\
\text { dari karet }\end{array}$ & 2,3 \\
\hline \multicolumn{1}{|c|}{ Total } & 7,9 & $\begin{array}{l}\text { Mengatur jalan } \\
\text { lintasan karet } \\
\text { agar tidak } \\
\text { menumpuk }\end{array}$ & 2,2 \\
\hline
\end{tabular}

Perhitungan Waktu Baku Total

Tabel 3.10 Perhitungan Total Waktu Baku

\begin{tabular}{|l|c|l|c|}
\hline \multicolumn{2}{|c|}{ Operator 1 } & \multicolumn{2}{c|}{ Operator 2 } \\
\hline $\begin{array}{c}\text { Elemen } \\
\text { Pekerjaan }\end{array}$ & $\begin{array}{c}\text { Waktu } \\
\text { Baku } \\
\text { Total } \\
\text { (Menit) }\end{array}$ & \multicolumn{1}{c|}{$\begin{array}{c}\text { Elemen } \\
\text { Pekerjaan }\end{array}$} & $\begin{array}{c}\text { Waktu } \\
\text { Baku } \\
\text { Total } \\
\text { (Menit) }\end{array}$ \\
\hline $\begin{array}{l}\text { Memotong sudut } \\
\text { karet }\end{array}$ & 53,2 & $\begin{array}{l}\text { Menggulung dan } \\
\text { melipat plastik }\end{array}$ & 59,4 \\
\hline $\begin{array}{l}\text { Memasukkan } \\
\text { karet ke plastik }\end{array}$ & 52 & $\begin{array}{l}\text { Mengambil karet } \\
\text { dari mesin } \\
\text { pengepresan dan } \\
\text { meletakkan ke } \\
\text { troli }\end{array}$ & 60 \\
\hline $\begin{array}{l}\text { Menimbang } \\
\text { karet }\end{array}$ & 58 & $\begin{array}{l}\text { Mengambil } \\
\text { kotoran } \\
\text { kontaminasi) } \\
\text { dari karet }\end{array}$ & 64,4 \\
\hline
\end{tabular}



dalam Bidang Teknik Industri

\begin{tabular}{|c|c|c|c|}
\hline $\begin{array}{l}\text { Pengecekan } \\
\text { karet }\end{array}$ & 54 & $\begin{array}{l}\text { Mengatur jalan } \\
\text { lintasan karet } \\
\text { agar tidak } \\
\text { menumpuk }\end{array}$ & 55 \\
\hline Total & 217,2 & Total & 238,8 \\
\hline
\end{tabular}

\subsection{Perhitungan Beban Kerja Operator}

\section{Operator 1}

$$
\begin{aligned}
\text { Beban Kerja (BK) } & =\frac{\text { Total Waktu Baku }}{\text { Total Menit Pengamatan }} \\
& =\frac{217,2}{175} \\
& =1,24
\end{aligned}
$$

2. Oparator 2

$$
\begin{aligned}
\text { Beban Kerja (BK) } & =\frac{\text { Total Waktu Baku }}{\text { Total Menit Pengamatan }} \\
& =\frac{238,8}{175} \\
& =1,36
\end{aligned}
$$

\section{Kebutuhan Tenaga Kerja Berdasarkan Beban} Kerja

Beban kerja yang diperoleh dari operator 1 adalah 1,24, sedangkan pada operator 2 adalah 1,36. Nilai tersebut berguna untuk mengetahui kebutuhan tenaga kerja dengan cara beban kerja kedua operator dibagi dengan jumlah operator (2 operator).

$$
\begin{aligned}
\text { Total beban kerja } & =1,24+1,36 \\
& =2,6
\end{aligned}
$$

1. Kondisi Awal

Pada kondisi awal terdapat 2 orang operator dengan nilai total beban kerja yang didapat adalah 2,6. Rata-rata beban kerja kondisi awa

$=\frac{2,6}{2}$

$=1,3$

Berdasarkan perhitungan diatas, maka terlihat beban kerja yang diterima masih dalam kondisi berat karena $\mathrm{BK}>1$, oleh karena itu akan dilakukan usulan penambahan beban kerja menjadi 3 orang sebagai berikut.

Rata-rata beban kerja kondisi akhir

$=\frac{2,6}{3}$

$=0,86$

2. Kondisi Penambahan Tenaga Kerja

Setalah didapatkan hasil dari perhitungan beban kerja pada kondisi awal, maka terdapat penambahan operator yang awalnya 2 operator menjadi 3 operator. Beban kerja yang diterima oleh operator sebesar 0,86 , dimana kondisi BK $<1$ yang berarti beban kerja yang diterima dalam kondisi ringan.

\section{Kesimpulan}

Kesimpulan dari penelitian ini adalah sebagai berikut:

1. Waktu baku yang dibutuhkan dalam menyelesaikan pekerjaan packing untuk operator 1 adalah 7,9 menit, sedangkan operator 2 dibutuhkan waktu 9,2 menit untuk menyelesaikan suatu pekerjaan.

2. Perlu adanya penambahan 1 orang operator sehingga total operator sebanyak 3 orang dengan tujuan mengurangi beban kerja pada operator.

3. Beban kerja yang diterima oleh operator sebesar 0.86 atau lebih kecil dari 1 yang artinya beban kerja masih dalam kondisi ringan.

\section{Daftar Pustaka}

Ferdian, Andrico. Studi Penerapan Beban Kerja yang Optimal dan di Evaluasi Dengan Metoda ECPM dan ECPT serta Strain Physiology pada Proses Produksi di CV. Aneka Jaya Gypsum Medan. Skripsi. Universitas Sumatera Utara Medan,

Izzhati, Dwi Nurul dan Dhieka Anendra. Implementasi Metode Work Sampling Guna Mengukur Produktivitas Tenaga Kerja di CV. Sinar Krom Semarang. Seminar, Nasional Teknologi Informasi dan Komunikasi Terapan bekerja sama dengan Universitas Dian Nuswantoro, Semarang. 2012.

Munandar, Duwar dkk. Usulan Perhitungan Insentif Karyawan CV. Miracle Berdasarkan Jumlah Produks.Jurnal OnlineInstitut Teknologi Nasional. Vol. 1, No. 1, halaman 226-237, Juli 2013.

Pracinasari, Ira. Beban Kerja Fisik vs Beban Kerja Mental. Laporan Penelitian.Hiperkes dan 
Keselamatan Kerja.Universitas Sebelas Maret, Surakarta. 2013.

Sutalaksana, Iftikar Z, dkk. "Teknik Tata Cara Kerja”Penerbit Institut Teknologi Bandung, Bandung. 1979.

Trisnawati. Usulan Pengurangan Biaya Tenaga Kerja Produksi dengan Pemilihan Sistem Kerja atau Penambahan Tenaga Kerja di PD. Maxshoi Helmet. Skripsi. Universitas Bina Nusantara, Jakarta. 2007.

Widyanti, A. dkk. Pengukuran Beban Kerja Mental dalam Searching Task dengan Metode Rating Scale Mental Effort (RSME). Jurnal J@TI Undip. Vol. 5, No. 1, halaman 1-6 I, Januari 2010.

Wignjosoebroto, Sritomo. "Ergonomi Studi Gerak dan Waktu" Edisi Pertama Cetakan ke Empat, Penerbit Guna Widya, Surabaya. 2008. 